\title{
Circadian variation in fat concentration of breast-milk in a rural northern Thai population
}

\author{
BY DOROTHY A. JACKSON ${ }^{1}$, STELLA M. IMONG ${ }^{1}$, A. SILPRASER T ${ }^{1}$, \\ S. RUCKPHAOPUNT ${ }^{1}, M$. W. WOOLRIDGE ${ }^{2}$, J. D. BAUM ${ }^{2}$ \\ AND K. AMATAYAKUL ${ }^{1}$ \\ ${ }^{1}$ Research Institute for Health Sciences, Chiang Mai University, P.O. Box 80 CMU, \\ Chiang Mai 50002, Thailand \\ ${ }^{2}$ Department of Child Health, University of Bristol, St Michael's Hill, Bristol BS2 8BJ
}

(Received 10 July 1987 -Accepted 27 November 1987)

\begin{abstract}
1. Twenty-five northern Thai mothers, breast-feeding their infants on demand, were studied in their homes for $24 \mathrm{~h}$. All breast-feeds were test-weighed and pre- and post-feed expressed breast-milk samples (0-5 ml) taken at each feed.

2. The fat concentration of milk taken during a feed showed significant circadian variation, with maximum values between 16.00 and 20.00 hours and minimum values between 04.00 and 08.00 hours. Fat concentration at the start and at the end of a feed also varied significantly over $24 \mathrm{~h}$.

3. Multiple regression analysis showed that the most important predictor of fat concentration at a feed was the length of time elapsed since the previous feed - the longer this interval, the lower the subsequent fat concentration. Other significant predictors were the fat concentration at the end of the previous feed, and the milk intake at the previous and at the current feed.

4. Fat concentration declined between feeds in proportion to the length of time between feeds, but the decline was less between sleep feeds than between waking feeds. This would appear to be a reflection of the lower postfeed fat concentration and higher pre-feed fat concentration of sleep feeds compared with waking feeds, when other variables relating to feeding pattern are taken into account.

5. The larger the milk intake at a feed, the greater was the increase in fat concentration from the start to the end of the feed. The change in fat concentration was less in feeds taking place during the sleep period than in daytime feeds.
\end{abstract}

Fat is the main source of energy of the breast-fed infant. Fat is also the most variable constituent of breast-milk, fluctuating in concentration over the course of a $24 \mathrm{~h}$ period (Hytten, $1954 a$; Prentice et al. 1981 a; Brown et al. 1982) and also rising during individual breast-feeds (Williams et al. 1986). Information on variation in breast-milk fat concentration is useful for planning breast-milk sampling procedures to obtain representative measures of the infant's energy intake. Descriptions of variations in breast-milk composition may also contribute to an understanding of those aspects of the physiology of human lactation which are not amenable to in vivo experimentation.

Most of the information on circadian variation in breast-milk fat concentration was obtained from studies carried out in the West when scheduled feeding of the infant was fashionable. Breast-milk was therefore sampled at regular intervals corresponding to feeds (Deem, 1931; Hytten, $1954 a$; Hall, 1979) or with extra scheduled samples taken during the night (Nims et al. 1932; Gunther \& Stainier, 1949). Except for Hall (1979), these studies determined milk composition from the complete manual or mechanical expression of breast contents (i.e. the infant did not actually feed at the breast) representing the quality of milk produced by the mother, but not necessarily that received by the infant, since infants can satiate before they have emptied the breast (Drewett \& Woolridge, 1981). Hall (1979) sampled breast-milk before and after every scheduled feed, as approximating to the composition of milk ingested by the infant.

Two recent studies have been carried out in developing countries, where demand-feeding 
is the normal practice. In The Gambia, milk was sampled before and after every feed, allowing mothers to follow their normal feeding patterns (Prentice et al. 1981 a), while in Bangladesh, total breast contents were expressed at three-hourly intervals, i.e. a regular sampling schedule was imposed on a demand-feeding study group (Brown et al. 1982).

The above studies have reported differing patterns of circadian variation in breast-milk fat concentration. This might be due to ethnic differences, to different breast-feeding practices, different study methods or simply random effects due to the small numbers of subjects participating in some of the studies. More information is required. Here we present results from a study in rural northern Thailand, examining the variation in fat concentration within and between demand-feeding mothers with minimal interference to natural breastfeeding patterns.

\section{METHODS}

After obtaining informed consent, twenty-five mother-baby pairs were studied in their homes in the district of Sanpatong, Chiang Mai Province, northern Thailand. The study was approved by the Research Institute's ethical committee. The mothers had been delivered, without complications, of healthy term infants weighing more than $2.5 \mathrm{~kg}$ at birth. Of the mothers, $56 \%$ had already successfully breast-fed one infant, the remainder were primiparae. The median age of the mothers was 29 (range 20-39) years. The age distribution of infants was: six infants aged 1 month old or less, eight infants 2-3 months old, six infants 4-6 months old and five infants 7-9 months old. Mean infant weight was $5 \cdot 59$ (range $3 \cdot 3-9 \cdot 35$ ) $\mathrm{kg}$.

The infants studied were exclusively or predominantly breast-fed. In Sanpatong, the median age of first introduction of non-breast-milk foods (including liquids such as orange juice) is 4 weeks, but regular consumption of solid foods generally begins between 2 and 3 months of age. Up to the age of 6 months, supplementary foods are given in small amounts, contributing only $20 \%$ on average to the total energy intake. After 6 months of age, supplementary foods supply on average $39 \%$ of energy intake in those children who are still being breast-fed (D. A. Jackson, unpublished observations).

The study day covered a $24 \mathrm{~h}$ period from 08.00 to 08.00 hours the following morning. During this time, all breast-feeds were timed and test-weighed on a portable K-Tron electronic averaging balance (resolution $1 \mathrm{~g}$; K-Tron Waagen AG, Industriestr 6, CH-8618 Oetwil am See, Switzerland) by a member of the field research team. Breast-milk $(0.5 \mathrm{ml})$ was manually expressed by the mother immediately before she put her baby to the breast and immediately after her baby came off the breast, and collected into separate $1 \mathrm{ml}$ plastic tubes. At night, mother and infant slept side-by-side in the parental bedroom, as is the custom in northern Thailand. (On the night of the study the father usually chose to sleep elsewhere.) Before each breast-feed, the mother informed the field team night-shift, who were waiting outside the bedroom. The field staff then test-weighed the baby and supervised collection of milk samples as described previously. To ensure that no night-time feeds were missed, routine checks were made every hour using a red-filtered flashlight, and any movement in the bedroom (easily heard in the simple wooden or bamboo houses) was also investigated. In the absence of baseline observations before the study, it was not possible to quantify the extent to which the study procedures interfered with normal suckling patterns. However, our impression was that daytime feeding behaviour was not affected, while there may have been some reduction in the number of night-time feeds.

Handling and storage of milk samples were carefully standardized to prevent changes in composition (Silprasert et al. 1986). Fat concentration of each sample was determined using the creamatocrit technique (Lucas et al. 1978) and the following conversion formula obtained at the Research Institute (Silprasert et al. 1986):

$$
\text { fat }(\mathrm{g} / \mathrm{l})=6.24 \text { creamatocrit }(\%)-3.08 \quad(95 \% \text { confidence limits } \pm 4.39 \mathrm{~g} / 1, n 65) \text {. }
$$


The fat concentration of the milk taken during a feed was calculated as the mean of the fat concentrations before and after the baby was attached to the breast. Additional information on the variation in fat concentration and variation in milk flow rate during the course of a feed would be necessary to permit more accurate estimation of overall fat concentration during a feed. However, the sampling technology to achieve these aims is still under development (Jackson et al. 1987).

\section{RESULTS}

Variation in fat concentration between mothers and between breasts within mothers In this population there was an approximately $2 \cdot 5$-fold variation between mothers in breast-milk fat concentration with $24 \mathrm{~h}$ values ranging from 20 to $49 \cdot 1$ (mean $34 \cdot 0$ (SD 7.0)) $\mathrm{g} / \mathrm{l}$. Waking fat concentration varied from 17.9 to 50.6 (mean 34.4 (SD 7.5 )) g/1 and fat concentration during the sleep period ranged from 20.7 to 45.7 (mean 31.4 (SD 6.6)) $\mathrm{g} / 1$.

Mean 24-h milk intake was 641 (SD 170, range 250-932) g, mean waking intake was 459 (SD 129, range 144-632) g, and mean sleep intake was 182 (SD 69, range 77-361) g. Mean feed frequency was 15 (SD 6, range 6-32) feeds per $24 \mathrm{~h}$.

Fat concentration of feeds differed significantly between mothers (two-level analysis of variance (left and right breast nested within mothers), $F_{(24,328)}=7.84, P<0.001$ ). The best single predictor of mothers' mean $24 \mathrm{~h}$ breast-milk fat concentration was infant age (log transformed) $(r-0.418, P=0.04)$, i.e. the older the baby the lower the fat concentration. There was no improvement in prediction when additional variables relating to feeding behaviour, namely $24 \mathrm{~h}$ milk intake, frequency of suckling and mean milk intake per breast were included in the regression analysis, possibly because these independent variables were correlated with the age of the infant. Maternal age and parity, and infant weight were also not significant.

There was no significant difference in fat concentration between the two breasts (twolevel nested ANOVA, left/right breast nested within mothers, $F_{(25,328)}=1 \cdot 14, P>0 \cdot 1$ ).

\section{Circadian variation in fat concentration within mothers}

To examine the circadian variation in fat concentration the mean fat concentrations for each $4 \mathrm{~h}$ period throughout the day (e.g. 08.00-12.00 hours, 12.00-16.00 hours, etc.) were calculated for each mother. Six of the twenty-five mothers did not feed in one or more periods, so their values were excluded. In view of the large differences between mothers in average milk fat concentration, the mean $4 \mathrm{~h}$ fat concentrations for each mother were standardized relative to her mean $24 \mathrm{~h}$ value, using $z$-scores. Linear and curved (quadratic) trends were then fitted to these time profiles (by extracting polynomials in a one-way analysis of variance (Armitage, 1983)).

The fat concentration of the milk taken during feeds rose from 08.00 hours to a peak between 16.00 and 20.00 hours, and then decreased to minimum levels between 04.00 and 08.00 hours the following morning. Thus fat concentration tended to be above average during the daytime and below average when the mother was asleep. This rise and fall in fat concentration (quadratic trend) was significant at $P=0.03$ (Fig. 1(a)).

The two variables from which fat concentration at a feed was calculated, the pre- and post-feed fat concentrations, were examined separately for circadian variation. Pre-feed fat concentration showed significant fluctuation over $24 \mathrm{~h}$ : below average during the morning and early afternoon, increasing to maximum values between 20.00 hours and midnight, followed by a decline to below average values between 04.00 and 08.00 hours the next morning. The quadratic component was significant at $P=0.038$ (Fig. 1(b)). Post-feed fat concentration increased from 08.00 hours to peak levels between 16.00 and 20.00 hours, and then showed a sharp drop during the remainder of the study period, with minimum 

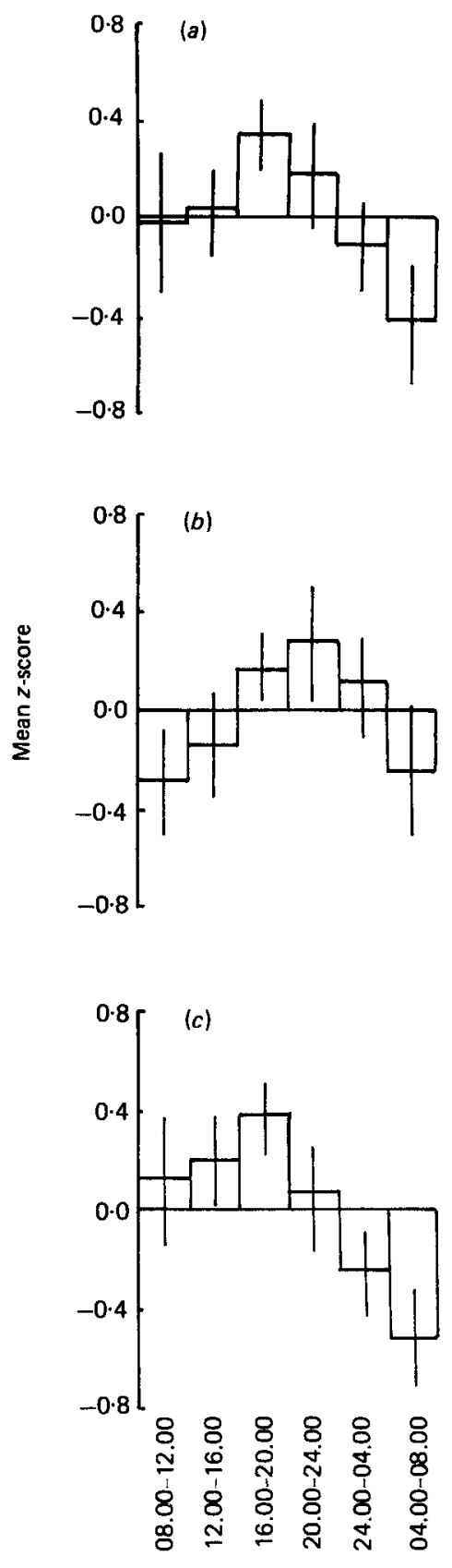

Time of day (hours)

Fig. 1. Circadian variation in $(a)$ mean fat concentration at a feed, $(b)$ fat concentration at the start of a feed and $(c)$ fat concentration at the end of a feed for nineteen northern Thai mothers. Each mother's mean $4 \mathrm{~h}$ breast-milk fat concentrations were calculated as a $z$-score of her overall mean; histograms show mean $z$-scores for nineteen mothers in each of the $4 \mathrm{~h}$ segments of time with their standard errors of means represented by vertical bars. 
levels between 04.00 and 08.00 hours. The decrease in post-feed fat concentration during the study period (linear component) was significant at $P=0 \cdot 004$, and the quadratic component was significant at $P=0 \cdot 05$ (Fig. $1(c)$ ).

\section{Variation in fat concentration at a feed}

Definition of a breast-feed. Over half the mothers ( $n 14)$ always fed their baby at only one breast at each feed, and the remainder mostly gave one-breast-feeds except for one mother who always gave two breasts at a feed. Overall, therefore, in $80 \%$ of the feeds, the infant was suckled at only one breast and in only $20 \%$ of feeds were both breasts given. Multiple regression analysis of variation in fat concentration in the first and second breasts of twobreast-feeds gave essentially the same results as analysis of one-breast-feeds. A breast-feed was therefore defined as milk intake from one breast, reflecting the predominant feeding pattern in this study group. If a second breast was offered at the same feed it was treated as an independent breast-feed.

Multiple regression analysis. Standard multiple linear regression analysis (Tabachnik \& Fidell, 1983) was used to explore variations in fat concentration in relation to infant feeding behaviour.

Variables anticipated to be predictors of the fat concentration at the start of a feed (PREFAT) were the milk intake at the previous feed on that breast (PREVINTAKE) (a measure of the degree to which that breast was previously emptied), the fat concentration attained at the end of the previous feed on that breast (PREVFAT), the time elapsed since the end of the previous feed on that breast (Prevtime), and whether the feed took place during the mother's sleep period or not (SLEEP, coded as $0=$ non-sleep feed, $1=$ sleep feed).

Predictor variables for the fat concentration at the end of a feed (PosTFAT) were PREFAT, the milk intake during the feed (INTAKE); time (min) spent on the breast (Duration); and SLEEP.

A third analysis was carried out using these six independent variables to predict fat concentration of milk consumed during a feed (FeEdFat, calculated as (Prefat + Postrat)/ 2). Additional analyses examined the decline in fat concentration from the end of one feed to the beginning of the next feed (Declfat, calculated as Prevfat-Prefat), the change in fat concentration during a feed (ChANGefat, calculated as Postfat-Prefat), and the milk intake and duration of feeds.

Variables were converted to $z$-scores relative to each mother's mean. Values for all twenty-five mothers are presented here; the subset comprising the nineteen mothers selected above for the analysis of circadian patterns gave similar results. Feeds with missing values for one or more variables in a particular analysis were not included in that analysis; no attempt was made to substitute for missing data. This may have introduced a bias into the multiple regression analysis, as most of the missing data occurred in the first left and first right breast-feeds of the day, because Prevtime, Prevfat and Previntake could not be calculated for these feeds. Fig. 1 suggests that the excluded feeds would have tended to have average mean fat values, below average pre-fat values and above average post-fat values. Prefat, Duration, Intake and Prevtime were positively skewed, but residuals from multiple regression analysis showed no major deviation from normality or homoscedascity. Logarithmic transformation of skewed variables did not affect residuals or regression statistics, therefore we present results using untransformed variables The significance levels presented for regression coefficients assume that the variable in question was entered last into the equation, i.e. that all other variables in the equation are held constant.

Fat concentration at the beginning of a feed ( $\mathrm{n} 319$ feeds). Altogether, $23 \%$ of the variance in fat concentration at the beginning of a feed was explained by the four independent 
Table 1. Multiple regression analysis of variations in fat concentration of breast-milk in a rural northern Thai population

\begin{tabular}{|c|c|c|c|c|c|}
\hline & & $B$ & $\beta$ & $R^{2}$ & Constant \\
\hline \multicolumn{6}{|c|}{$\begin{array}{l}\text { (a) Predictors of fat concentration at the start } \\
\text { of a feed (PREFAT) ( } n 319 \text { feeds) }\end{array}$} \\
\hline & Prevtime & $-0.463^{* * *}$ & -0.452 & $0 \cdot 230$ & $-0 \cdot 090$ \\
\hline & Prevfat & $0 \cdot 286^{* * *}$ & $0 \cdot 283$ & & \\
\hline & SLEEP & $0.505^{* * *}$ & $0 \cdot 231$ & & \\
\hline & PREvintake & 0.089 & $0 \cdot 088$ & & \\
\hline \multirow[t]{5}{*}{ (b) } & $\begin{array}{l}\text { Predictors of fat concentration at the end } \\
\text { of a feed (PosrFAT) (n } 369 \text { feeds) }\end{array}$ & & & & \\
\hline & PRefat & $0 \cdot 355^{* * *}$ & $0 \cdot 353$ & $0 \cdot 205$ & $0 \cdot 165^{* *}$ \\
\hline & INTAKE & $0 \cdot 322 * * *$ & $0 \cdot 321$ & & \\
\hline & SLEEP & $-0.650^{* * *}$ & $-0 \cdot 287$ & & \\
\hline & DURATION & $0 \cdot 114^{* *}$ & $0 \cdot 109$ & & \\
\hline \multirow[t]{7}{*}{ (c) } & $\begin{array}{l}\text { Predictors of mean fat concentration during } \\
\text { a feed (FEEDFAT) ( } n 315 \text { feeds) }\end{array}$ & & & & \\
\hline & Prevtime & $-0 \cdot 425^{* * *}$ & -0.424 & $0 \cdot 259$ & $-0 \cdot 015$ \\
\hline & PREVfat & $0 \cdot 275^{* * *}$ & $0 \cdot 279$ & & \\
\hline & Previntake & $0 \cdot 177^{* * *}$ & $0 \cdot 180$ & & \\
\hline & INTAKE & $0 \cdot 131^{*}$ & $0 \cdot 130$ & & \\
\hline & DURATION & $0 \cdot 101$ & 0.099 & & \\
\hline & SLEEP & 0.027 & $0 \cdot 013$ & & \\
\hline
\end{tabular}

$\beta$, standardized regression coefficient, whose magnitude is independent of the scale of measurement of that variable; Prevtime, time elapsed since previous feed; PreVfat, fat concentration at end of previous feed; SLEEP, whether feed took place during mother's sleep period $(0=$ non-sleep feed, $1=$ sleep feed $)$; PrevinTAKE, milk intake at previous feed; PrEFAT, fat concentration at start of feed; INTAKE, milk intake during feed; DURATION, time (min) spent on the breast.

$* P<0.05, * * P<0.01, * * * P<0.001$.

variables (Table $1(a)$ ). The best predictor (shown by the $\beta$ value) of fat concentration at the start of the feed was the time elapsed since the previous feed on that breast (PrevTIME): the longer the time elapsed, the lower the subsequent fat concentration $(P<0 \cdot 001)$. In addition, the higher the fat concentration at the end of the previous feed on that breast, the higher the fat concentration at the start of the next feed $(P<0.001)$. The milk intake at the previous feed was not significantly correlated.

If confounding variables were ignored, there was no correlation between fat concentration at the start of a feed and whether the feed took place in the sleep period or not ( $r$ 0.04). However, if PREVTIME was held constant the semi-partial correlation coefficient between Prefat and SLEEP was highly significant $(r 0.207, P<0.001)$. This indicates that for a given period of time since the previous feed from a breast, pre-feed fat concentration was greater if the feed took place during the mother's sleep period (Table $1(a)$ ). These associations are summarized in Fig. $2(a)$.

Fat concentration at the end of a feed (n 369 feeds). The greater the concentration of fat at the start of a feed, the greater the fat concentration at the end of that feed, when all the other variables were held constant $(P<0.001)$. Fat concentration at the end of a feed was also higher when milk intake was greater $(P<0.001)$ and feed duration was longer $(P=$ 0.03). With PREFAT, INTAKE and Duration held constant, post-feed fat concentration was less during sleep feeds than during waking feeds $(P<0.001)$. These four predictor variables explained $21 \%$ of the variance in post-feed fat concentration (Table 1(b)). Associations between variables are shown in Fig. 2(b). 
(a)
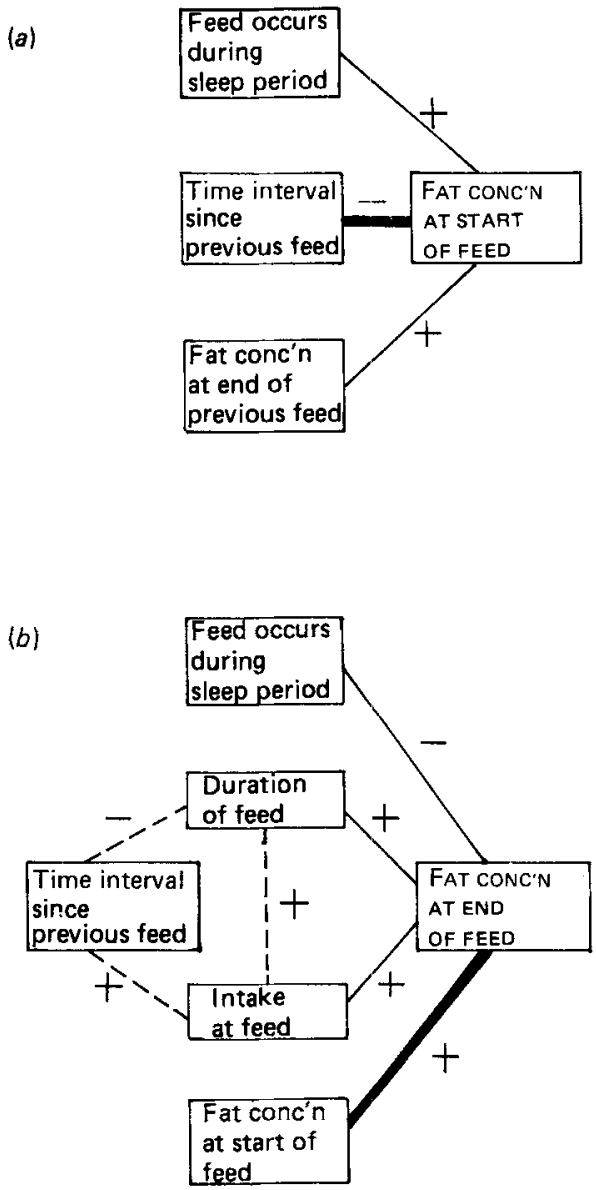

Fig. 2. Significant associations between independent variables and (a) fat concentration at the start of a feed and $(b)$ fat concentration at the end of a feed, derived from multiple regression analysis. (Strong association; (--), associations between independent variables; +, positive association; negative association.

Fat concentration during a feed (mean of pre-feed and post-feed fat concentrations (n 315 feeds). With all other variables taken into account, the most important predictor of fat concentration of milk consumed during a feed was the period of time elapsed since the previous feed on that breast; the longer the interval, the lower the fat concentration of the feed $(P<0$-001). In addition, higher fat concentration at a feed was associated with higher fat concentration at the end of the previous feed $(P<0.001)$, a larger intake at the previous feed $(P<0.001)$, or a larger intake at the current feed $(P=0.029)$ (Table $1(c))$. Feed duration was not significantly correlated. Altogether, $26 \%$ of variation in feed fat concentration was explained.

The two previous analyses showed that when the other variables were held constant, the fat concentration at the start of a feed was higher and the fat concentration at the end of a feed was lower during sleep feeds compared with waking feeds. Due to these two opposing effects, whether the feed took place during the sleep period or not did not contribute significantly to the prediction of fat concentration of milk taken during a feed. Thus, although the fat concentration was lower during the sleep period (Fig. 1(a)), this was an 
Table 2. Multiple regression analysis of variation in fat concentration between feeds, change in fat concentration during feeds, milk intake and feed duration of breast-milk in a rural northern Thai population

\begin{tabular}{|c|c|c|c|c|c|}
\hline & & $B$ & $\beta$ & $R^{2}$ & Constant \\
\hline \multirow[t]{4}{*}{ (a) } & $\begin{array}{l}\text { Predictors of decline in fat concentration } \\
\text { between feeds (DECLFAT) ( } n 319 \text { feeds) }\end{array}$ & & & & \\
\hline & Prevtime & $0 \cdot 458^{* * *}$ & 0.451 & $0 \cdot 175$ & $-0 \cdot 119^{*}$ \\
\hline & SLEEP & $-0.401^{* *}$ & -0.185 & & \\
\hline & Previntake & $0 \cdot 108^{*}$ & $0 \cdot 108$ & & \\
\hline \multirow[t]{4}{*}{ (b) } & $\begin{array}{l}\text { Predictors of change in fat concentration during } \\
\text { a feed (CHANGEFAT) ( } n 369 \text { feeds) }\end{array}$ & & & & \\
\hline & INTAKE & $0 \cdot 460 * * *$ & 0.460 & 0.247 & $0 \cdot 165^{* *}$ \\
\hline & SLEEP & $-0.650 * * *$ & $-0 \cdot 287$ & & \\
\hline & DURATION & 0.052 & 0.050 & & \\
\hline \multirow[t]{5}{*}{ (c) } & Predictors of milk intake (INTAKE) ( $n 315$ feeds) & & & & \\
\hline & PREVTIME & $0 \cdot 473^{* * *}$ & 0.475 & 0.304 & 0.075 \\
\hline & DURATION & $0 \cdot 283^{* * *}$ & $0 \cdot 278$ & & \\
\hline & Previntake & $0 \cdot 013$ & 0.013 & & \\
\hline & SLEEP & $0 \cdot 032$ & 0.015 & & \\
\hline \multirow[t]{5}{*}{ (d) } & $\begin{array}{l}\text { Predictors of feed duration (DuRation) } \\
\text { ( } n 315 \text { feeds) }\end{array}$ & & & & \\
\hline & INTAKE & $0.348 * * *$ & 0.353 & $0 \cdot 117$ & $-0 \cdot 028$ \\
\hline & Prevtime & $-0 \cdot 247^{* * *}$ & -0.252 & & \\
\hline & SLEEP & $0 \cdot 281^{*}$ & 0.134 & & \\
\hline & Previntake & -0.004 & -0.004 & & \\
\hline
\end{tabular}

$\beta$, standardized regression coefficient, whose magnitude is independent of the scale of measurement of that variable; PrEVTIME, time elapsed since previous feed; SLEEP, whether feed took place during mother's sleep period $(0=$ non-sleep feed, $1=$ sleep feed); PreVintake, milk intake at previous feed; INTAKE, milk intake during feed; Duration, time (min) spent on the breast.

* $P<0.05, * * P<0.01$, *** $P<0.001$.

indirect effect of the association with other variables in the analysis; principally the period of time elapsed since the last feed, which was longer during the sleep period (bivariate correlation: $r 0.433, P<0.001)$.

Decline in fat concentration between feeds ( 319 feeds). Fat concentration of breast-milk declined between the end of one feed and the start of the next feed at that breast. The decline in fat concentration was greater the longer the time interval between feeds $(P<$ $0.001)$ or the greater the intake at the previous feed $(P=0.04)$. When the period of time elapsed between feeds was taken into account, the decline in fat concentration since the previous feed was less for feeds during the sleep period than for waking feeds $(P=0.0013)$. This agrees with the previously described results, in which fat concentration at the start of a feed was higher during sleep feeds, and fat concentration at the end of a feed was lower during sleep feeds, thus reducing the difference between the fat concentration at the end of one feed and that at the start of the next (Table 2(a)).

Change in fat concentration during a feed ( 369 feeds). On average, fat concentration increased by a factor of 2.3 from the start to the end of a feed (SD 1.92, range 0.35-21.85). In $6 \%$ of feeds, fat concentration increased more than fivefold and in $9 \%$ of feeds, fat concentration decreased from the start to the end of the feed. The change in fat concentration during a feed was greater the greater the feed volume $(P<0.001)$, and with feed volume taken into account, feeds which took place during the sleep period had a smaller increase in fat concentration $(P<0.001)$. This confirms the previous observations 

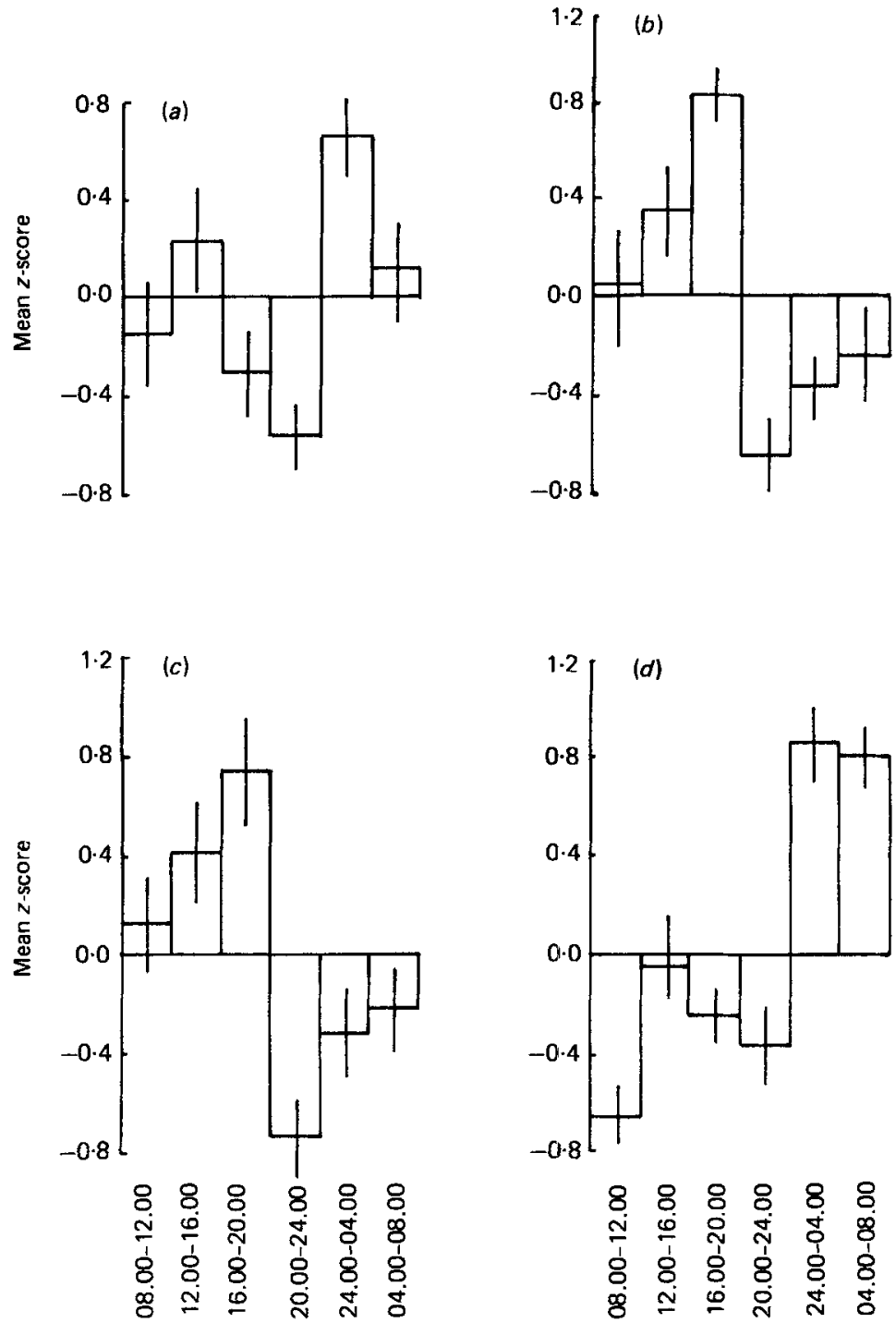

Time of day (hours)

Fig. 3. Circadian variation in (a) milk intake at a feed, $(b)$ total fat intake over a $4 \mathrm{~h}$ period, $(c)$ total milk intake over a $4 \mathrm{~h}$ period, $(d)$ period of time elapsed since previous feed of breast-milk from northern Thai mothers. Each mother's mean $4 \mathrm{~h}$ values are calculated as the $z$-score of her overall mean. Histograms show mean $z$-scores with their standard errors represented by vertical bars for nineteen mothers except in $(d)$ at $08.00-12.00$ hours, where period of time since previous feed could only be calculated for the nine mothers who fed more than once from left or right breasts during this time period.

that the amplitude of fat change within and between feeds was reduced during the sleep period. Feed duration was not a significant predictor (Table 2(b)).

Milk intake and duration of feed. Table 2(c) shows the results of multiple regression analysis of predictors of milk intake. Milk intake at a feed was greater the longer the period of time elapsed since the previous feed, and the longer the feed duration (both significant at $P<0.001$ ). When these two variables were held constant, the volume of the previous feed 
and whether the feed took place during the sleep period had no additional significant predictive power. Milk intake varied significantly over the $24 \mathrm{~h}$ study period $(P=0 \cdot 045)$, but as the variations were erratic, they could not be fitted with either a linear or a quadratic trend (Fig. 3(a)).

The results of multiple regression analysis on feed duration are shown in Table $2(d)$. The most important variables associated with feed duration were the milk intake at the feed and the time elapsed since the previous feed. The bivariate correlation between feed duration (DURATION) and time elapsed since the previous feed (PrevTime) was -0.026 , but when the other independent variables were held constant the semi-partial correlation coefficient between these two variables increased to $-0.206(P<0.001)$. The variable masking the interaction between DURATION and PREVTIME was INTAKE, which was positively correlated with PREVTIME (see above). Thus, for a given milk intake, the longer the period of time since the previous feed, the shorter the feed duration, i.e. the faster the rate of milk transfer (see Fig. $2(b))$.

Variation in fat intakes. Mean $24 \mathrm{~h}$ fat intake was 21.6 (SD 6.9, range 8.9-35.7) g, with a mean waking fat intake of 15.9 (SD 5.9, range 6.0-27.9) $\mathrm{g}$ and mean sleep fat intake of 5.7

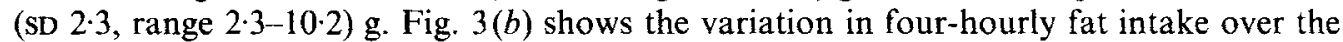
$24 \mathrm{~h}$ period. The linear trend was significant $(P<0.001)$ as was the cubic component (the rise, fall and subsequent rise $)(P<0.001)$. The marked fall in fat intakes between 20.00 and 08.00 hours was due to the reduced total milk intakes during this period (Fig. 3(c)). Although average feed volume was greater (Fig. 3(a)), fewer feeds were given during the sleep period and as fat concentration of feeds was also less at night (Fig. 1(a)) there was no possibility of compensating for lower milk intake.

\section{DISCUSSION}

Variation in fat concentration between mothers and between breasts within mothers Mean $24 \mathrm{~h}$ fat concentration was lower in mothers with older infants. Prentice et al. (1981 b) reported decreasing fat concentration from the first to the fourth trimester of lactation. The observation that fat content of breast-milk decreases with increasing parity (Lauber \& Reinhardt, 1979; Prentice et al. 1981 b) was not obtained in our study, possibly because the range in parity in this study was very small. Other variables relating to the feeding patterns of the infants, such as milk intake and frequency of suckling, did not predict mean fat concentration as well as the age of the infant, either singly or in combination with other variables. Differences between mothers may be due to maternal variables such as diet, nutritional status or genetic variation.

In this study, no consistent difference in fat concentration was found between breasts within individual women, confirming the findings of Prentice et al. (1981a) and Neville et al. (1984).

\section{Circadian variation in fat concentration}

The concentration of fat in the milk of northern Thai mothers varied significantly over the $24 \mathrm{~h}$ study period. The fat concentration of feeds occurring in successive four-hourly episodes (corrected for differences between mothers) rose from 08.00 hours to maximum levels by late afternoon and early evening (16.00 to 20.00 hours), and then declined to minimum levels at the end of the night and in the early morning ( 04.00 to 08.00 hours).

Published data on circadian variation in breast-milk fat concentration are summarized graphically in Fig. 4. The northern Thai pattern is $180^{\circ}$ out of phase with that observed in The Gambia and Bangladesh. In The Gambia, mothers demand-fed and milk was sampled before and after each feed, while in Bangladesh breast contents were expressed at three- 


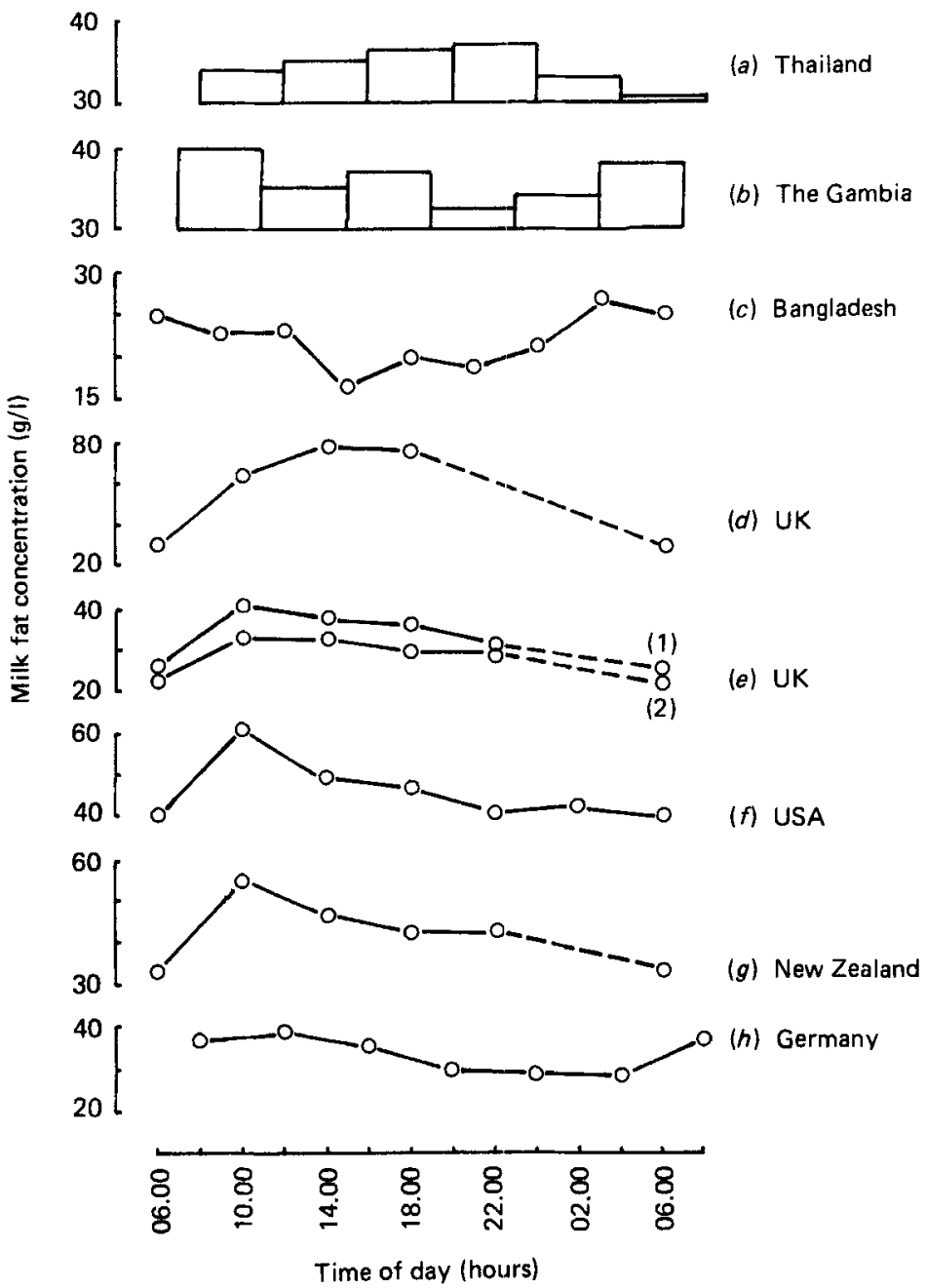

Fig. 4. Circadian variation in fat concentration of breast-milk from published studies. Note that the shape of $(a)$ differs slightly from that of Fig. $1(a)$ because differences between mothers in mean fat concentration have not been corrected. (a) Thailand (present study). Demand feeding, pre-/post-feed expressed samples, nineteen mothers studied for $24 \mathrm{~h}$ each, infants aged $1-9$ months. $(b)$ The Gambia (Prentice et al. 1981 a). Demand feeding, pre-/post-feed expressed samples, sixteen mothers studied for $24 \mathrm{~h}$ each, infants aged 1-18 months. (c) Bangladesh (Brown et al. 1982). Demand feeding, but samples collected at scheduled intervals by total breast extraction (breast pump), seven mothers studied for $24 \mathrm{~h}$ each, infants aged 1-9 months. (d) UK (Hall, 1979). Scheduled feeding, pre-/post-feed expressed samples, one mother studied for $72 \mathrm{~h}$, age of infant not specified. (e) UK (Hytten, 1954a). Scheduled feeding, samples collected by total breast extraction (breast pump), (1) twenty-nine mothers studied for $24 \mathrm{~h}$ each, infants aged 3-8 d, (2) twenty mothers studied for $24 \mathrm{~h}$ each, infants aged $21 \mathrm{~d}-4 \mathrm{months}$. ( $f$ ) USA (Nims et al. 1932). Scheduled feeding, samples collected by total breast extraction (manual), three mothers studied, but values only given for one mother, studied for $24 \mathrm{~h}$ on six occasions and $72 \mathrm{~h}$ on one occasion, infant aged 6-60 weeks. (g) New Zealand (Deem, 1931). Scheduled feeding, samples collected by total breast extraction (manual), twenty-eight mothers studied for $24 \mathrm{~h}$ each, infants aged 1-8 months. (h) Germany (Gunther \& Stainier, 1949). Scheduled feeding, collection of samples by total breast extraction (manual), two mothers studied for $24 \mathrm{~h}$ each, six mothers studied for $52 \mathrm{~h}$ each, infants aged 8-11 d. 
hourly intervals. Despite differences in the sampling methods, both studies reported high fat concentrations at the end of the night and in the early morning, and low concentrations during the late afternoon and early evening (Prentice et al. 1981a; Brown et al. 1982). Studies carried out in Western countries, by expression of total breast contents at scheduled intervals, revealed a third type of variation: lowest fat concentrations occurred in the early morning, followed by a rapid rise to highest values in the late morning. Fat concentration subsequently declined gradually over the rest of the $24 \mathrm{~h}$ period (Deem, 1931; Nims et al. 1932; Gunther \& Stainier, 1949; Hytten, 1954a). In one Western study, where sampling took place before and after each meal but at scheduled times, the rise in fat concentration was shifted to the early afternoon, i.e. intermediate between the pattern observed in the other Western countries and in Thailand. However, this result was obtained by studying one mother only, and may therefore not be representative (Hall, 1979).

The similarities and differences between the patterns of variation shown in Fig. 4 do not clearly correspond to similarities and differences in sampling methods (extraction of total breast contents or pre- and post-feed sampling), timing of feeds (scheduled or demand), 'lifestyle' (industrialized West or less developed countries) or ethnicity (Caucasian, African or Asian). The feeding behaviour of the infant, however, is significantly correlated to variations in fat concentration, and may contribute to the patterns of circadian variation shown in Fig. 4.

\section{Feeding behaviour and variations in fat concentration}

Multiple regression analysis showed that the period of time since the previous feed on a breast and the fat concentration attained at the end of that feed were the most important predictors of the fat concentration at the beginning of the next feed on that breast. In turn, the fat concentration at the beginning of a feed and the milk intake at that feed were the most important predictors of the fat concentration attained at the end of the feed. Thus the fat concentration during a given feed was partly related to previous feeding behaviour which predicted initial fat concentration, and partly to current feeding behaviour which predicted the final fat concentration.

The most important predictor of fat concentration at a feed was the period of time elapsed since the previous feed on that breast; the longer the period of time elapsed, the lower the fat concentration. This probably accounts for the lower fat concentrations observed in sleep feeds, when the time interval between feeds is longer than that during the day. A negative association between mean fat concentration and time since the preceding feed was also found (for daytime feeds only) among demand-feeding infants in The Gambia (Prentice et al. 1981 a) and in schedule-feeding British infants (Kon \& Mawson, 1950). The observed low, early morning fat concentrations in some studies where samples were taken at scheduled times but not at night (Deem, 1931; Hytten, 1954 $a$; Hall, 1979) could reflect the long interfeed interval preceding the first feed of the day. Low, early morning fat concentration was also observed in studies where additional samples (expressed breast contents) were taken during the night (Nims et al. 1932; Gunther \& Stainier, 1949) indicating that the time interval between feeds, though important, is not the only variable underlying circadian variation in fat concentration. This is shown simply by the fact that the curve of $4 \mathrm{~h}$ means of time interval since the preceding feed (Fig. $3(d)$ ) was not an exact inversion of the curve for $4 \mathrm{~h}$ mean fat concentration (Fig. 1(a)). Multiple regression analysis also demonstrated that several independent variables were correlated with fat concentration.

Many of the correlations observed in northern Thailand were also reported in The Gambia (Prentice et al. 1981a). In addition to the relation between mean feed fat concentration and period of time between feeds cited above, both studies found that fat concentration at a feed was positively associated with the milk intake at the previous feed, 
that milk intake and the decrease in fat concentration between feeds were positively related to the period of time since the last feed, and that the change in fat concentration from start to end of the feed was greater when more milk was consumed during the feed. The Gambian study found no relation between mean fat concentration at a feed and the intake at a feed, but in the present study this (relatively weak) association only became apparent when other feed variables were controlled through multiple regression analysis. Although there was no relation between the mean fat concentration and volume of individual feeds, The Gambian study reported that, at the population level, average fat concentrations tended to be highest when average milk intakes were lowest. No such inverse relation was found in the present study (compare Fig. 1(a) with Fig. 3(a)).

Since milk intake at the previous feed was found to be correlated with subsequent fat concentration, obtaining milk samples by expression of the total breast contents (thus simulating feeding) may distort patterns of variation in fat concentration. Under natural conditions a variable amount of milk is left in the breast after a feed (Khin-Maung-Naing et al. 1980). Greater than normal removal of milk by complete stripping of the breast may affect subsequent milk synthesis and will also sample a proportion of high fat hind milk which the infant may not necessarily remove (Drewett \& Woolridge, 1981).

\section{Other sources of variation in fat concentration}

Variations in feeding behaviour were correlated with variation in fat concentration between feeds, but up to $79 \%$ of the variance in fat concentration remained unexplained by the measured variables.

One factor which was not examined in this study but which could relate to variation in breast-milk fat concentration is the timing and composition of the mother's meals. In women on high-fat diets, most milk fat is derived from dietary fat. If the diet is low in fat but adequate in carbohydrate, a larger percentage of milk fat is synthesized in the breast from glucose, and on a low-energy diet, body-fat stores are mobilized to form milk lipids (Neville \& Neifert, 1980). Differences in milk-lipid secretion depending on ethnic differences in diet and timing of meals and the predominant synthetic pathway could contribute to the temporal patterns of milk-fat concentration shown in Fig. 4. However, available information on maternal diet and circadian changes in milk-fat concentration is equivocal. Read et al. (1965) observed that the fatty acid composition of milk reflected earlier maternal dietary intake, but did not report changes in total fat concentration. Consumption of an abnormally large quantity of fat at one meal was followed by an increase in breast-milk fat concentration 12 h later (Ruzicic (1936), quoted in Gunther \& Stainier, 1949), but fasting or feeding mothers during their sleep period did not alter the circadian variation in breastmilk fat concentration (Gunther \& Stainier, 1949).

The circadian variation in fat concentration could relate in some way to circadian changes in background hormone secretion, for example prolactin, which is involved in the regulation of lipid synthesis (Neville \& Neifert, 1980) and shows higher basal serum levels during the sleep period (Sassin et al. 1972; Bunner et al. 1978; Gross et al. 1979). At present, this must remain conjectural as it is not clear how quickly changes in prolactin levels are followed by changes in fat concentration (Tyson et al. 1973).

In the present study, a difference was observed between daytime and night-time fat concentrations which appeared to be independent of day/night changes in feeding behaviour: feeds which occurred during the mother's sleep period had higher fat concentrations at the start of the feed and lower fat concentrations at the end of the feed than daytime feeds, and fat concentration declined more slowly between sleep feeds than between daytime feeds, even after day/night differences in inter-feed time interval and milk intake were taken into account. 
These observations could reflect nocturnal changes in synthesis of fat or aqueous fractions or alternatively a redistribution of fat globules within the breast. Fat, being less dense than the aqueous phase, may partially separate out, causing local differences in its distribution in stored milk. This is believed to underlie the characteristic rise in fat concentration during the course of a breast-feed (Hytten, 1954 $b$; Neville \& Neifert, 1980). The altered posture at night, horizontal and relatively inactive, rather than the more active and vertical state during the daytime, may permit the fat to accumulate more anteriorly and so predispose towards milk of a higher fat concentration being taken earlier in the feed. Removal of more of the fat at the beginning of the feed would tend to reduce the fat concentration in the remainder of the feed, giving lower post-feed fat concentrations relative to daytime. Overall, the fat concentration of the feed would not be greatly affected since all that has changed is the distribution of a given quantity of fat in the breast. Multiple regression analysis showed that whether a feed took place during the sleep period or not did not contribute significantly to the prediction of the average fat concentration of milk removed during a feed.

Variation in fat concentration of breast-milk is related to many variables, including feeding behaviour and probably also maternal diet and hormone secretion. Patterns observed in one study cannot yet be generalized and applied to other populations. At present it is therefore necessary to carry out pilot studies to assess variation in breast-milk composition in each study population if appropriate sampling procedures for representative measures of nutrient intake are to be devised. The accompanying paper (Jackson et al. 1988) presents an evaluation of various breast-milk sampling procedures for the northern Thai population described in this study.

The work on which this paper is based was supported by the Royal Thai Government and the International Development Research Centre (IDRC), Canada. Individual personnel received funding from the following organizations: D.A.J., The Wellcome Trust and The Nestlé Nutrition Research Grants Programme; S.M.I., Overseas Development Administration; M.W.W., Commission of the European Communities, R \& D Programme 'Science and Technology for Development', contract TSD-156. This study is part of the Thai-UK collaborative Chiang Mai Lactation Project. Additional members of the steering committee and research group include: (in Chiang Mai) P. Chiowanich, S. Silpisornkosol, L. Wongsawasdii, Y. Yootabootr, A. Tansuhaj, K. Rungruengthanakit; (in Bristol) A. F. Williams; (in Durham) R. F. Drewett. The nurses and aides of the field research team carried out field observations and data collection; Sakda Preunglumpoo and Posri Leelapat performed the creamatocrit determinations. Their help is gratefully acknowledged.

\section{REFERENCES}

Armitage, P. (1983). Statistical Methods in Medical Research. Oxford: Blackwell Scientific Publications.

Brown, K. H., Black, R. E., Robertson, A. D., Aktar, N. A., Ahmed, G. \& Becker, S. (1982). American Journal of Clinical Nutrition 35, 745-756.

Bunner, D. L., VanderLaan, E. F. \& VanderLaan, W. P. (1978). American Journal of Obstetrics and Gynecology 131, $250-252$.

Deem, H. E. (1931). Archives of Disease in Childhood 6, 53-61.

Drewett, R. F. \& Woolridge, M. W. (1981). Physiology and Behaviour 26, 327-329.

Gross, B. A., Eastman, C. J., Bowen, K. M. \& McElduff, A. (1979). Australian and New Zealand Journal of Obstetrics and Gynaecology 19, 150-153.

Gunther, M. \& Stainier, J. E. (1949). Lancet ii, 235-237.

Hall, B. (1979). American Journal of Clinical Nutrition 32, 304-312.

Hytten, F. E. (1954a). British Medical Journal i, 179-182.

Hytten, F. E. (1954b). British Medical Journal i, 176-179. 
Jackson, D. A., Imong, S. M., Silprasert, A., Preunglumpoo, S., Leelapat, P., Yootabootr, Y., Amatayakul, K. \& Baum, J. D. (1988). British Journal of Nutrition 59, 365-371.

Jackson, D. A., Woolridge, M. W., Imong, S. M., McLeod, C. N., Yutabootr, Y., Wongsawat, L., Amatayakul, K. \& Baum, J. D. (1987). Early Human Development 15, 295-306.

Khin-Maung-Naing, Tin-Tin-Oo, Kywe-Thein \& Nwe-Nwe-Hlaing (1980). American Journal of Clinical Nutrition 33, 2665-2668.

Kon, S. K. \& Mawson, E. H. (1950). Special Report Series of the Medical Research Council no. 269, pp. $18-24$.

Lauber, E. \& Reinhardt, M. (1979). American Journal of Clinical Nutrition 32, 1159-1173.

Lucas, A., Gibbs, J. A. H., Lyster, R. L. J. \& Baum, J, D. (1978). British Medical Journal i, 1018-1020.

Neville, M. C., Keller, R. P., Seacat, J., Casey, C. E., Allen, J. C. \& Archer, P. (1984). American Journal of Clinical Nutrition 40, 635-646.

Neville, M. C. \& Neifert, M. R. (1980). Lactation. New York and London: Plenum Press.

Nims, G., Macy, I. C., Brown, M. \& Hunscher, H. A. (1932). American Journal of Diseases of Children 43 , $828-844$.

Prentice, A., Prentice, A. M. \& Whitehead, R. G. (1981a). British Journal of Nutrition 45, 483-494.

Prentice, A., Prentice, A. M. \& Whitehead, R. G. (1981 b). British Journal of Nutrition 45, 495-503.

Read, W. W. C., Lutz, P. G. \& Tashjian, A. (1965). American Journal of Clinical Nutrition 17, 184-187.

Sassin, J, F., Frantz, A. G., Weitzman, E. D. \& Kapen, S. (1972). Science 177, 1205-1207.

Silprasert, A., Dejsarai, W., Keawvichit, R.\& Amatayakul, K. (1986). Human Nutrition: Clinical Nutrition 40C, 31-36.

Tabachnik, B. G. \& Fidell, L. S. (1983). Using Multivariate Statistics. New York: Harper \& Row.

Tyson, J. E., Friesen, H. G. \& Anderson, M. S. (1973). In Hypothalamic-Hypophysiotropic Hormones, pp. $396-403$ [C. Gual and E. Rosenberg, editors]. Amsterdam: Excerpta Medica.

Williams, A. F., Akinkugbe, F. M. \& Baum, J. D. (1986). Human Nutrition: Clinical Nutrition 39 C, 193-202. 